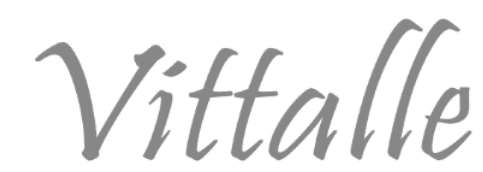

\title{
A realidade de idosos que vivem com AIDS no Brasil: uma revisão integrativa
}

\author{
Amanda Martinelli*, Alleha Lima Luzzi, Elisa Maria Faria Guedes, Isadora Cabral de \\ Melo Abrahao, João Eduardo Martins Ponce, Maria Julia Calheiros Santos Diniz, \\ Veronica de Souza Rosa, Maria Elisa Gonzalez Manso \\ Centro Universitário São Camilo, São Paulo, SP, Brasil
}

\author{
Histórico do Artigo: \\ Recebido em: \\ 15/02/2021 \\ Aceito em: \\ $25 / 04 / 2021$
}

Palavras-chave: Idosos; HIV/AIDS; qualidade de vida.

Keywords:

Elderly; HIV/AIDS; quality of life.

\begin{abstract}
RESUMO
A epidemia de HIV/AIDS atingiu seu pico na década de 1990 e vitimou milhões de pessoas pelo mundo antes do desenvolvimento de tratamentos. Hoje, o diagnóstico não é mais uma sentença de morte e cresceu o número de idosos que vivem com a doença, seja porque contraíram jovens e sobreviveram, seja porque se infectaram tardiamente. Torna-se, assim, relevante analisar as percepções sociais e as condições de vida do idoso com HIV no Brasil. O objetivo deste estudo foi verificar o conhecimento científico produzido sobre a visão da sociedade, a visão dos profissionais de saúde, e sobretudo a visão do idoso sobre a própria sorologia positiva para HIV, além de analisar a adesão ao tratamento antirretroviral. Trata-se de uma revisão integrativa da literatura e, para tal, foram consultadas as bases de dados Biblioteca Virtual de Saúde (BVS) e Coordenação de Aperfeiçoamento de Pessoal de Nível Superior (CAPES). Foram identificados inicialmente 127 textos, dos quais foram selecionados para análise 10 artigos, formando 3 categorias: Visão da Sociedade e do Profissional de Saúde; Visão do Idoso; Tratamento do Idoso com HIV/AIDS. A partir dos resultados encontrados, conclui-se que os idosos portadores de HIV estão mais vulneráveis, pois não recebem a devida atenção da sociedade e dos profissionais de saúde, contribuindo com um diagnóstico tardio, o que afeta na adesão ao tratamento.
\end{abstract}

The reality of elderly people living with AIDS in Brazil: an integrative review.

\begin{abstract}
The HIV/AIDS epidemic reached its peak in the 1990's and killed millions of people around the world before the development of treatments. Nowadays, the diagnosis is no longer a death sentence and the number of elderly people living with the disease has grown, either because they caught it at a young age and survived, or as a result of late contamination. It is, therefore, relevant analyzing the social perceptions and living conditions of elderly people living with HIV in Brazil. The aim of this study was to verify the scientific knowledge produced regarding society's point of view, healthcare workers' point of view, and overall, the elderly's point of view of its own perspective of positive serology for HIV, besides analyzing the adhesion for the antiretroviral treatment. This is an integrative literature review for which the consulted databases were Virtual Health Library (VHL) and Coordination of Superior Level Staff Improvement (CSLSI). Initially, a total of 127 texts were found, from which 10 articles were selected for analysis, divided in 3 categories: Society and Healthcare Workers' Point of View; Elderly People's Point of View; Treating the Elderly Living with HIV/AIDS. From the findings, it was concluded that elderly people with HIV are more vulnerable, because they do not get the necessary attention from society and healthcare workers, contributing to a late diagnosis, which affects treatment adhesion.
\end{abstract}

\section{Introdução}

No Brasil, a AIDS - Síndrome da imunodeficiência humana adquirida (AIDS - em inglês: Acquired immunodeficiency syndrome) foi descrita no mesmo ano em que o termo surgiu, 1982. Desde então, o perfil epidemiológico mudou consideravelmente, migrando de um cenário em que o vírus do HIV - Vírus da Imunodeficiencia Humana

\footnotetext{
*Autor correspondente: amandaa.martinelli@gmail.com (Martinelli A.)
} 
(HIV - em inglês: Human immunodeficiency virus) era associado apenas a alguns grupos específicos, principalmente homossexuais e usuários de drogas, à situação atual, em que o vírus se apresenta de forma mais homogênea na sociedade, atingindo heterossexuais, mulheres e idosos, independente de classe social ou região do país (1).

Os casos notificados para a população idosa, na faixa etária igual ou superior a 60 anos, têm apresentado um aumento progressivo para ambos os sexos, passando de $855 \mathrm{em} 2007$ para 1649 em 2020 (2). Habitualmente são considerados idosos os indivíduos com 60 anos ou mais (3). Porém, devido principalmente ao quadro clínico e aos impactos da doença no organismo, quando se trata de estudos epidemiológicos referentes ao HIV/AIDS, são consideradas idosas as pessoas a partir dos 50 anos (4).

A elevação da prevalência de HIV em idosos está relacionada tanto ao fato de as pessoas poderem se contaminar através do sexo desprotegido em idades mais avançadas, quanto à maior expectativa de vida daqueles que já apresentavam o vírus antes de chegarem aos 60 anos (5). Esse aumento da expectativa de vida se deu principalmente pelo desenvolvimento da terapia antirretroviral combinada (TARV) em 1996, que permitiu a supressão crônica da replicação do HIV, proporcionando uma melhoria na qualidade de vida dos portadores de HIV/AIDS, além de ter representado um marco legal de acesso universal ao tratamento de AIDS, uma vez que, desde então, o Brasil oferece os antirretrovirais gratuitamente aos pacientes $(6,7)$. Essa terapêutica foi responsável também por diminuir a incidência de infecções oportunistas, um dos maiores perigos aos soropositivos que desenvolvem a imunodeficiência, e por reduzir o desenvolvimento de demência. Apesar disso, transtornos psiquiátricos como depressão ainda são bastante comuns nas interconsultas de portadores do vírus, configurando mais um desafio na adesão ao tratamento e na manutenção da qualidade de vida.

Apesar dos benefícios ofertados pelo sistema de saúde, é possível apontar falhas graves no momento de diagnosticar o HIV em pessoas idosas. Os profissionais de saúde muitas vezes não consideram os idosos como indivíduos sexualmente ativos, e tendem a associar os sintomas apresentados a outras doenças que não o HIV, podendo trazer complicações aos pacientes devido ao diagnóstico tardio $(8,9)$. Ademais, a falta de preparo dos profissionais da saúde para lidar com a sexualidade dos idosos acaba sendo um obstáculo não apenas à detecção das ISTs (Infecções sexualmente transmissíveis) como o HIV, mas também na prevenção delas, e o acolhimento oferecido ao paciente nem sempre é adequado no momento do diagnóstico, fator importante no sucesso do tratamento a longo prazo.

A falha do sistema de saúde quanto à divulgação de informações sobre a doença acaba estimulando uma percepção antiga e equivocada sobre a epidemiologia do HIV, e não apenas fortalece uma visão estigmatizada por parte da sociedade para com esses pacientes, como também reforça preconceitos do próprio paciente sobre sua condição, influenciando negativamente na adesão e continuidade do tratamento e, consequentemente, em sua qualidade de vida (10).

Dessa forma, a partir da complexidade referente à questão do HIV/AIDS em idosos, sintetizar informações a respeito do tema nessa faixa etária é uma interessante ferramenta para o desenvolvimento de possíveis estratégias que melhorem a adesão ao tratamento e a consequente qualidade de vida dos portadores. Nesse sentido, esse estudo teve como objetivo verificar o conhecimento científico produzido sobre a visão da sociedade, a visão dos profissionais de saúde, e sobretudo a visão do idoso sobre a própria sorologia positiva para HIV, além de analisar a adesão ao tratamento antirretroviral. 


\section{Metodologia}

Trata-se de um estudo em formato de revisão, realizado durante o segundo semestre de 2020, sob a ótica de população/paciente, interesse e contexto (PIC) e feito a partir da base de dados Literatura Latino-americana e do Caribe em Ciências da Saúde (LILACS).

As buscas foram feitas a partir dos descritores "idoso", "HIV" e "AIDS", combinados pelo operador booleano AND. Além disso, também foram aplicados os filtros, "últimos 5 anos", "texto completo", "LILACS", encontrando 225 artigos. Aplicando os filtros de assunto principal com os termos "Infecções por HIV", "Síndrome de Imunodeficiência Adquirida", "Soropositividade para HIV", "Conhecimento, Atitudes e Prática em Saúde", restaram 93 artigos. Adotaram-se como critérios de inclusão: a) artigos publicados últimos 5 anos; b) pesquisas cujo tema central fosse AIDS em idosos; c) idioma em português e inglês; d) artigos completos (pagos e gratuitos); e) ensaios clínicos, estudos de prevalência, estudos de corte e de caso controle; f) pesquisas qualitativas. Excluíramse: a) estudos anteriores ao ano de 2015 ; b) artigos que não abordaram os critérios de inclusão acima; c) estudos com o foco apenas no animal; d) estudos com outros animais que não cães; e) estudos com modelos experimentais animais; f) séries de casos, relatos de caso, revisões não sistemáticas e opiniões de especialistas.

Posteriormente, os títulos foram avaliados por todos os pesquisadores e foram excluídos os que não tinham AIDS em idosos como temática central, permanecendo então para o trabalho um total de 10 textos (Figura 1).
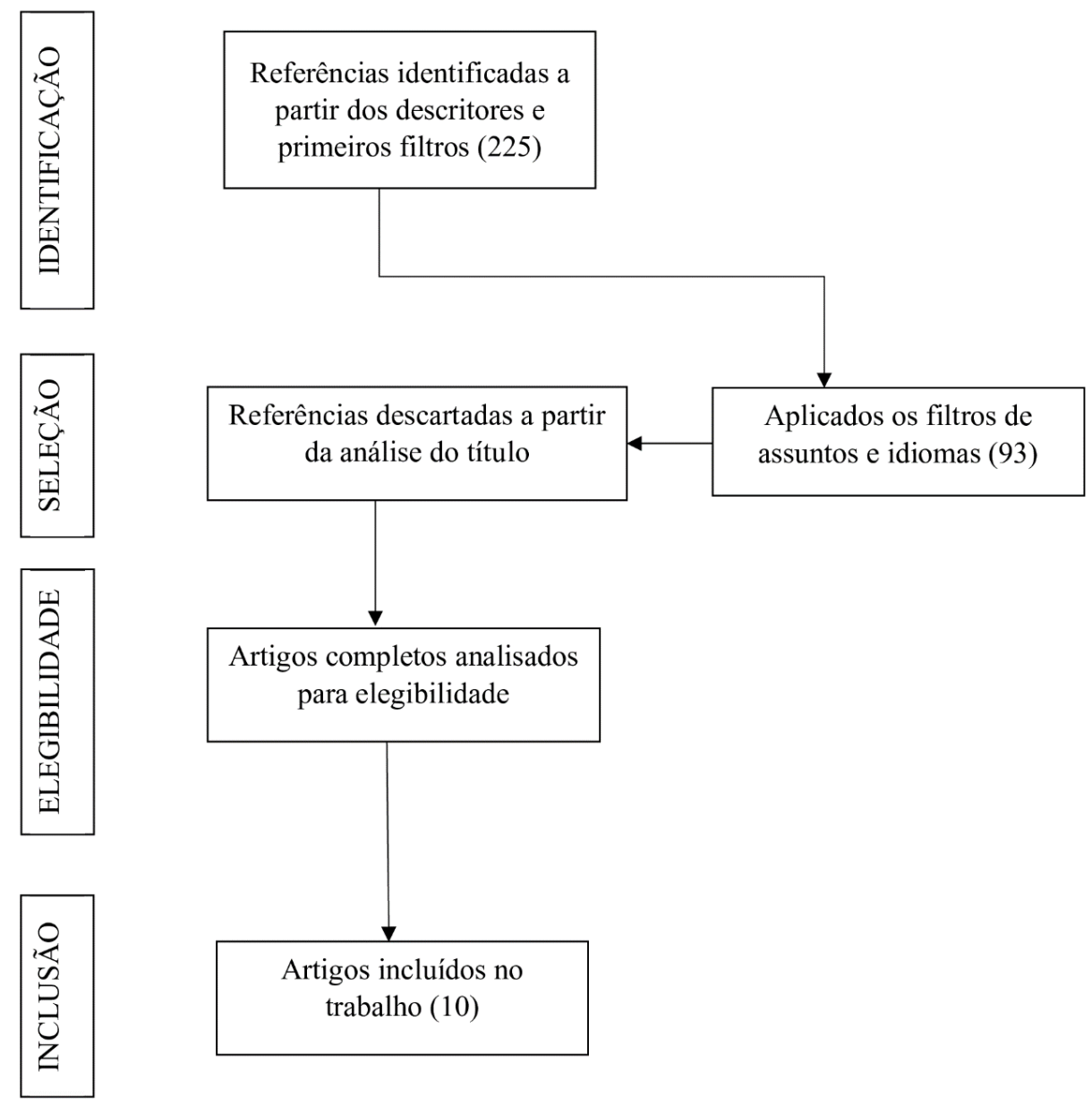

Artigos completos analisados para elegibilidade

Artigos incluídos no trabalho (10)

Figura 1 - Fluxograma dos artigos encontrados e selecionados por meio da pesquisa na base de dados 


\section{Resultados}

Os 10 estudos incluídos foram sumarizados no Quadro 1 quanto aos autores, tamanho e características da amostra, objetivo, método e resultados principais.

Quadro 1 - Sumário dos Artigos obtidos pela revisão, com a temática dos descritores: Idoso; HIV; AIDS.

\begin{tabular}{|c|c|c|c|}
\hline Amostra & Objetivo & Método & Resultados \\
\hline $\begin{array}{l}11 \text { idosos } \\
\text { com } \\
\text { HIV/AIDS } \\
(>=60 \text { anos), } \\
11 \\
\text { enfermeiros } \\
\text { e } 12 \\
\text { médicos. }\end{array}$ & $\begin{array}{l}\text { Investigar entre } \\
\text { os idosos } \\
\text { vivendo com } \\
\text { HIV/Aids e os } \\
\text { profissionais de } \\
\text { saúde, quais são } \\
\text { os motivos que } \\
\text { levam ao } \\
\text { diagnóstico } \\
\text { tardio da } \\
\text { infecção pelo } \\
\text { HIV nos idosos. }\end{array}$ & $\begin{array}{l}\text { Estudo prospectivo, } \\
\text { qualitativo, realizado em } \\
\text { ambulatório especializado } \\
\text { com idosos vivendo com } \\
\text { HIV/aids, diagnosticados } \\
\text { com idade igual ou superior a } \\
60 \text { anos e nas Unidades } \\
\text { Estratégia Saúde da Família } \\
\text { com enfermeiros e médicos. } \\
\text { Os dados foram coletados por } \\
\text { meio de entrevistas e } \\
\text { verificados por análise de } \\
\text { conteúdo, utilizando o } \\
\text { referencial teórico da } \\
\text { vulnerabilidade. }\end{array}$ & $\begin{array}{l}\text { Emergiram três categorias } \\
\text { empíricas: o diagnóstico } \\
\text { tardio do HIV acontece na } \\
\text { contramão do serviço de } \\
\text { saúde; invisibilidade da } \\
\text { sexualidade do idoso; e } \\
\text { fragilidades na solicitação da } \\
\text { sorologia anti-HIV para os } \\
\text { idosos. }\end{array}$ \\
\hline $\begin{array}{l}7 \text { artigos } \\
\text { selecionados } \\
\text { para análise }\end{array}$ & $\begin{array}{l}\text { Analisar a } \\
\text { produção } \\
\text { científica sobre } \\
\text { os aspectos } \\
\text { bioéticos } \\
\text { envolvidos no } \\
\text { cuidado ao } \\
\text { idoso com } \\
\text { HIV/AIDS. }\end{array}$ & $\begin{array}{l}\text { Realizou-se revisão } \\
\text { sistemática de artigos nas } \\
\text { bases de dados Scopus e } \\
\text { SciELO. }\end{array}$ & $\begin{array}{l}\text { Os estudos selecionados } \\
\text { indicaram que ocorreu } \\
\text { aumento do número de idosos } \\
\text { com HIV/AIDS; os idosos } \\
\text { possuem déficit de } \\
\text { conhecimento sobre as } \\
\text { formas de transmissão do } \\
\text { HIV; os profissionais de } \\
\text { saúde têm dificuldades de } \\
\text { abordar a sexualidade na } \\
\text { terceira idade. Evidenciou-se } \\
\text { que apesar das concepções } \\
\text { construídas em relação à } \\
\text { doença, o preconceito sobre a } \\
\text { sexualidade tem dificultado } \\
\text { medidas preventivas para a } \\
\text { infecção levando à } \\
\text { construção de estratégias de } \\
\text { resistência pelos idosos como } \\
\text { silêncio em relação à } \\
\text { sorologia, esperança da cura } \\
\text { da AIDS e busca do respeito } \\
\text { a autonomia. }\end{array}$ \\
\hline
\end{tabular}

continua 


\begin{tabular}{|c|c|c|c|}
\hline $\begin{array}{l}39 \text { idosos } \\
\text { com } \\
\text { HIV/AIDS } \\
(>=60 \text { anos) } \\
\text { que } \\
\text { frequentam } \\
\text { ambulatório } \\
\text { de idosos do } \\
\text { Instituto de } \\
\text { Infectologia } \\
\text { Emílio } \\
\text { Ribas. }\end{array}$ & $\begin{array}{l}\text { Verificar níveis } \\
\text { de depressão, } \\
\text { qualidade de } \\
\text { vida e adesão } \\
\text { ao tratamento } \\
\text { antirretroviral } \\
\text { em idosos } \\
\text { portadores de } \\
\text { HIV/Aids. }\end{array}$ & $\begin{array}{l}\text { Os instrumentos utilizados } \\
\text { foram: questionário sócio } \\
\text { demográfico, Inventário Beck } \\
\text { de depressão - (BDI), } \\
\text { questionário para avaliação } \\
\text { da adesão ao tratamento } \\
\text { antirretroviral, questionário } \\
\text { para avaliação da qualidade } \\
\text { de vida da organização } \\
\text { Mundial de saúde } \\
\text { (WHOQOL), Escala } \\
\text { Instrumental para Atividades } \\
\text { de Vida Diária e International } \\
\text { HIV Dementia Scale - IDHS. } \\
\text { A aplicação destes } \\
\text { instrumentos foi realizada no } \\
\text { Instituto de Infectologia } \\
\text { Emílio Ribas, nos meses de } \\
\text { agosto e setembro de } 2011 \\
\text { até agosto e setembro de } \\
\text { 2012. Foram realizadas } \\
\text { análises descritivas e de } \\
\text { correlação. }\end{array}$ & $\begin{array}{l}\text { Os resultados evidenciaram } \\
\text { que a depressão se relaciona } \\
\text { com o domínio psicológico } \\
\text { da qualidade de vida do } \\
\text { WHOQOL e com as } \\
\text { alterações cognitivas } \\
\text { avaliadas pelo Mini-exame } \\
\text { do estado mental - MEEM. } \\
\text { Em relação à adesão ao } \\
\text { tratamento antirretroviral, as } \\
\text { alterações cognitivas } \\
\text { associadas ao HIV } \\
\text { apresentaram relação e, não a } \\
\text { depressão como inicialmente, } \\
\text { se imaginava. }\end{array}$ \\
\hline $\begin{array}{l}13 \text { artigos } \\
\text { selecionados } \\
\text { para análise }\end{array}$ & $\begin{array}{l}\text { Identificar os } \\
\text { fatores que } \\
\text { influenciam a } \\
\text { qualidade de } \\
\text { vida de idosos } \\
\text { com o Vírus da } \\
\text { Imunodeficiênc } \\
\text { ia Humana e } \\
\text { discutir as } \\
\text { formas de } \\
\text { enfrentamento } \\
\text { dos fatores que } \\
\text { afetam a } \\
\text { qualidade de } \\
\text { vida. }\end{array}$ & $\begin{array}{l}\text { Revisão integrativa de } \\
\text { literatura cuja busca, } \\
\text { realizada na Literatura } \\
\text { Latino-americana e do Caribe } \\
\text { em Ciências da Saúde, US } \\
\text { National Library of Medicine } \\
\text { e Cumulative Index to } \\
\text { Nursing \& Allied Health } \\
\text { Literature, ocorreu nos dias } \\
21 \text { e } 22 \text { de novembro de } \\
2017 \text {. }\end{array}$ & $\begin{array}{l}\text { Foram encontrados } 24.122 \\
\text { artigos, dos quais } 13 \text { foram } \\
\text { selecionados para análise, } \\
\text { emergindo duas categorias: } \\
\text { Fatores que influenciam a } \\
\text { qualidade de vida de idosos } \\
\text { com o Vírus da } \\
\text { Imunodeficiência Humana; } \\
\text { Formas de enfrentamento dos } \\
\text { fatores que afetam a } \\
\text { qualidade de vida desses } \\
\text { idosos }\end{array}$ \\
\hline $\begin{array}{l}5 \text { idosos com } \\
\text { HIV/AIDS } \\
(>=60 \text { anos) } \\
\text { acompanhad } \\
\text { os em Centro } \\
\text { de Testagem } \\
\text { e } \\
\text { Aconselham } \\
\text { ento de um } \\
\text { município da } \\
\text { região } \\
\text { metropolitan } \\
\text { a de } \\
\text { Fortaleza, } \\
\text { Ceará. }\end{array}$ & $\begin{array}{l}\text { Compreender a } \\
\text { base ideológica } \\
\text { presente nas } \\
\text { vivências de } \\
\text { idosos com } \\
\text { diagnóstico de } \\
\text { infecção pelo } \\
\text { Vírus da } \\
\text { Imunodeficiênc } \\
\text { ia Humana } \\
\text { (HIV) e } \\
\text { Síndrome da } \\
\text { Imunodeficiênc } \\
\text { ia Adquirida } \\
\text { (AIDS). }\end{array}$ & $\begin{array}{l}\text { Estudo qualitativo, que } \\
\text { utilizou o método criativo e } \\
\text { sensível e a análise de } \\
\text { discurso francesa, realizado } \\
\text { em um encontro grupal com } \\
\text { cinco idosos acompanhados } \\
\text { em Centro de Testagem e } \\
\text { Aconselhamento de um } \\
\text { município da região } \\
\text { metropolitana de Fortaleza, } \\
\text { Ceará. }\end{array}$ & $\begin{array}{l}\text { Os relatos dos idosos } \\
\text { direcionaram a formação } \\
\text { discursiva Vida resignada, } \\
\text { atitude imobilizada!, } \\
\text { caracterizada por quatro } \\
\text { situações existenciais: } \\
\text { concepções controversas } \\
\text { sobre a violência física na } \\
\text { infância; um negócio } \\
\text { chamado AIDS; falta de } \\
\text { resposta e culpabilização } \\
\text { relacionadas à infecção pelo } \\
\text { HIV; amparo na fé. }\end{array}$ \\
\hline
\end{tabular}


continuação

\begin{tabular}{|c|c|c|c|}
\hline $\begin{array}{l}11 \text { idosos } \\
(>=60 \text { anos })\end{array}$ & $\begin{array}{l}\text { Identificar as } \\
\text { vulnerabilidade } \\
\text { s de idosos com } \\
\text { HIV/aids e o } \\
\text { caminho } \\
\text { percorrido por } \\
\text { eles até o } \\
\text { diagnóstico da } \\
\text { doença. }\end{array}$ & $\begin{array}{l}\text { Pesquisa qualitativa } \\
\text { conduzida em ambulatório } \\
\text { especializado no interior do } \\
\text { Estado de São Paulo, de } \\
\text { janeiro a junho de } 2011 . \\
\text { Realizou-se entrevista } \\
\text { semiestruturada com } 11 \\
\text { idosos que se descobriram } \\
\text { infectados com o vírus com } \\
\text { idade igual ou superior a } 60 \\
\text { anos. As entrevistas foram } \\
\text { analisadas utilizando a } \\
\text { análise de conteúdo. }\end{array}$ & $\begin{array}{l}\text { Desse processo emergiram } \\
\text { quatro categorias, que foram } \\
\text { analisadas à luz do } \\
\text { referencial teórico da } \\
\text { vulnerabilidade. O } \\
\text { diagnóstico tardio da infecção } \\
\text { por HIV ou aids entre os } \\
\text { idosos acontece no serviço } \\
\text { secundário ou terciário. }\end{array}$ \\
\hline $\begin{array}{l}142 \text { idosos } \\
\text { com } \\
\text { HIV/AIDS } \\
\text { (entre } 60 \text { e } \\
81 \text { anos) }\end{array}$ & $\begin{array}{l}\text { Avaliar a } \\
\text { capacidade } \\
\text { funcional de } \\
\text { idosos com } \\
\text { síndrome de } \\
\text { imunodeficiênci } \\
\text { a adquirida } \\
\text { (HIV/AIDS). }\end{array}$ & $\begin{array}{l}\text { Estudo transversal com } \\
\text { inquérito epidemiológico } \\
\text { observacional com a coleta } \\
\text { de dados realizada através de } \\
\text { entrevistas e fonte } \\
\text { documental de } 142 \text { idosos } \\
\text { portadores do vírus da } \\
\text { imunodeficiência humana, } \\
\text { entre } 60 \text { e } 81 \text { anos de idade, } \\
\text { avaliados pelos domínios de } \\
\text { funcionalidade cognitiva, } \\
\text { saúde mental e Atividades da } \\
\text { Vida Diária. Foram } \\
\text { realizadas análise absoluta e } \\
\text { relativa das variáveis } \\
\text { contínuas, além da associação } \\
\text { das variáveis independentes. }\end{array}$ & $\begin{array}{l}\text { Viviam com AIDS 82,39\% } \\
\text { dos idosos da amostra; } 35,2 \% \\
\text { deles tinham mais de } 9 \text { anos } \\
\text { de estudo e } 35 \% \text { usavam } \\
\text { maconha. Dentre eles, } 71,7 \% \\
\text { se contaminaram em relações } \\
\text { heterossexuais e } 70,3 \% \text { em } \\
\text { relações com múltiplos } \\
\text { parceiros. Constatou-se } \\
\text { satisfatória a adesão à terapia } \\
\text { antirretroviral. Foi } \\
\text { significativa a perda } \\
\text { funcional naqueles com } 70 \\
\text { anos ou mais de idade de } \\
\text { ambos os sexos. }\end{array}$ \\
\hline $\begin{array}{l}49 \text { idosos } \\
(>=60 \text { anos) } \\
\text { notificados } \\
\text { no hospital } \\
\text { do município } \\
\text { de Maceió } \\
\text { entre } 2001 \text { e } \\
2011 .\end{array}$ & $\begin{array}{l}\text { Traçar o perfil } \\
\text { dos casos de } \\
\text { Síndrome da } \\
\text { Imunodeficiênc } \\
\text { ia Adquirida em } \\
\text { idosos, } \\
\text { relatando assim } \\
\text { as } \\
\text { características } \\
\text { da doença na } \\
\text { realidade do } \\
\text { município de } \\
\text { Maceió. }\end{array}$ & $\begin{array}{l}\text { Estudo transversal, descritivo } \\
\text { e quantitativo, realizado em } \\
\text { um hospital de referência, } \\
\text { com uma amostra censitária } \\
\text { que incluiu os casos de AIDS } \\
\text { em idosos notificados na } \\
\text { instituição num período de } 10 \\
\text { anos. }\end{array}$ & $\begin{array}{l}\text { A faixa etária prevalente foi a } \\
\text { de } 63 \text { anos }(16,3 \%) \text {, sendo os } \\
\text { homens mais acometidos } \\
(81,6 \%) \text { que as mulheres } \\
(18,4 \%) \text {. O meio de } \\
\text { transmissão prevalente foi } \\
\text { através de relações sexuais } \\
\text { com mulheres }(49 \%) \text {, e o } \\
\text { grau de escolaridade mais } \\
\text { frequente foi o de } 5^{\mathrm{a}} \text { a } 8^{\mathrm{a}} \text { série } \\
\text { incompleta do Ensino } \\
\text { Fundamental }(16,3 \%) \text {. }\end{array}$ \\
\hline
\end{tabular}

continua 


\begin{tabular}{|c|c|c|c|}
\hline $\begin{array}{l}9 \text { idosos com } \\
\text { HIV/AIDS } \\
\text { (entre } 60 \text { e } \\
77 \text { anos) }\end{array}$ & $\begin{array}{l}\text { Conhecer como } \\
\text { pessoas idosas } \\
\text { com o vírus da } \\
\text { imunodeficiênci } \\
\text { a humana } \\
\text { (HIV) se } \\
\text { infectaram, } \\
\text { descobriram o } \\
\text { diagnóstico e } \\
\text { passaram a } \\
\text { conviver com o } \\
\text { HIV. }\end{array}$ & $\begin{array}{l}\text { Pesquisa qualitativa } \\
\text { exploratório-descritiva } \\
\text { realizada entre novembro e } \\
\text { dezembro de } 2012 \\
\text { entrevistou nove pessoas } \\
\text { idosas soropositivas } \\
\text { atendidas em uma unidade de } \\
\text { referência de um hospital } \\
\text { universitário do sul do Brasil. }\end{array}$ & $\begin{array}{l}\text { Os dados foram submetidos à } \\
\text { análise de conteúdo, } \\
\text { resultando em seis categorias: } \\
\text { (des)conhecimento sobre o } \\
\text { HIV/AIDS antes do contágio; } \\
\text { infecção pelo HIV; } \\
\text { descoberta do diagnóstico; } \\
\text { reação da pessoa idosa diante } \\
\text { do diagnóstico; } \\
\text { soropositividade e o cotidiano } \\
\text { da pessoa idosa; vida sexual e } \\
\text { prevenção após a descoberta } \\
\text { da infeccão por HIV. }\end{array}$ \\
\hline $\begin{array}{l}7 \text { artigos } \\
\text { selecionados } \\
\text { para análise }\end{array}$ & $\begin{array}{l}\text { Verificar o } \\
\text { conhecimento } \\
\text { científico } \\
\text { produzido sobre } \\
\text { o apoio social } \\
\text { aos idosos com } \\
\text { HIV/aids. }\end{array}$ & $\begin{array}{l}\text { Foram consultadas as bases } \\
\text { de dados Lilacs, Medline, } \\
\text { Scopus e Web of Science por } \\
\text { estudos realizados nos } \\
\text { últimos } 10 \text { anos. A análise } \\
\text { final foi realizada com sete } \\
\text { artigos. }\end{array}$ & $\begin{array}{l}\text { Verificou-se que há uma } \\
\text { grande importância do apoio } \\
\text { social na vida dos idosos com } \\
\text { HIV/aids, bem como } \\
\text { mostrou-se uma real } \\
\text { necessidade deles quanto a } \\
\text { esse suporte. Este suporte } \\
\text { pode tanto contribuir de } \\
\text { diversas formas para a } \\
\text { qualidade de vida, como } \\
\text { prejudicar o cuidado da } \\
\text { pessoa que vive com a } \\
\text { doença, pois o diagnóstico, o } \\
\text { tratamento e todo o estigma } \\
\text { que rodeia essa condição } \\
\text { crônica influenciam } \\
\text { diretamente no tipo e na } \\
\text { qualidade do apoio que lhe é } \\
\text { fornecido. }\end{array}$ \\
\hline
\end{tabular}

\section{Discussão}

\section{Visão da Sociedade e dos Profissionais de Saúde}

De acordo com o Boletim epidemiológico AIDS e IST de 2017 do Ministério da Saúde foram registrados 1125 casos de HIV em 2015. Já no ano seguinte, foram registrados 1294 casos, ou seja, houve um aumento de 15\% em apenas 1 ano (11). Esse aumento deve-se a causas multifatoriais, destacando-se a invisibilidade da vida sexual do idoso, que contribui para falhas no diagnóstico e consequente tratamento tardio.

De acordo com Cassètte (12), a visão da sociedade é estigmatizada e preconceituosa em relação aos idosos portadores de HIV porque essa realidade diverge dos ideais de assexualidade nesse momento da vida. Nesse sentido, há um desejo do idoso de ocultar a sua sorologia positiva para HIV de todos à sua volta, levando essa população a preferir viver em casas de repouso, tanto pelo acolhimento quanto pelo tratamento que irão receber. A partir dessa situação, o idoso sente-se receoso a buscar ajuda familiar, resultando em um enfrentamento solitário da doença que os afeta psicologicamente e os reprime socialmente, pois deveriam estar amparados tanto pelos parentes quanto pelos profissionais de saúde (11).

Durante a década de 1980, houve a maior taxa de contaminação pelo vírus HIV, cuja 
letalidade impactou fortemente a sociedade como um todo. Entretanto, com o surgimento da Terapia Antirretroviral (TARV), ocorreu um declínio da mortalidade e aumento da longevidade (13). Apesar do aumento da expectativa de vida e da qualidade de vida dos idosos.

Quando um idoso com sintomas relacionados à sorologia positiva de HIV procura por atendimento na Atenção Primária à Saúde (APS), a suspeita inicial quase nunca é AIDS, mas sim doenças relacionadas ao envelhecimento. (14). Isso ocorre devido ao estigma sobre a vida sexual da população 50+, pois para alguns profissionais esses indivíduos não são sexualmente ativos. Dessa forma, o preconceito que reflete no atendimento dos profissionais de saúde destaca-se na APS, uma vez que se revela difícil o diálogo de médicos e enfermeiros sobre questões relacionadas à vida sexual dos idosos.

No Brasil, é notável o aumento do número de casos de HIV positivos da população com mais de 60 anos. Isso é evidenciado, por exemplo, pelos dados coletados de 2001 a 2011 no Hospital Escola Dr. Helvio Auto, onde foram contabilizados 49 casos de HIV, sendo 47 por transmissão sexual. Esse número evidencia que há prática sexual entre a população idosa (15). Nesse cenário, a prescrição da sorologia para HIV também é deficitária, pois, além de não ser rotina no serviço primário de saúde, alguns profissionais a solicitam apenas em casos de idosos viúvos, com muitas parceiras sexuais ou usuários de drogas. Salienta-se que idosos casados ou em relações estáveis não estão incluídos nesse grupo. Como tentativa de contornar essa situação, existe a campanha "Fique Sabendo" para realização da investigação, que ocorre uma vez ao ano, no Dia Mundial de Combate a AIDS (14).

A ausência da comunicação e a diferença na faixa etária entre os profissionais de saúde e os pacientes idosos com HIV prejudicam a compreensão do diagnostico, pois eles não recebem uma informação acessível sobre sua condição sorológica (13). Desse modo, percebe-se também uma falha na formação desses profissionais, em função dos cursos não abordarem a sexualidade do idoso (14) e formas de transmitir informações para essa população, o que dificulta um atendimento que compreenda o contexto sociocultural em que essas pessoas estão inseridas (16).

No sentido de adensar o corpo de estudo voltado para melhor atender a parcela de idosos soropositivos, são necessários estudos direcionados que analisem as dificuldades de viver com uma doença crônica e estigmatizante como a AIDS em diferentes sociedades. Isso é relevante não só pelas múltiplas formas como cada sociedade encara a doença como também pelo fato de cada lugar possuir diferentes agentes etiológicos (as vezes endêmicos) que ocasionam doenças oportunistas diversas.

Por exemplo, na América Latina há maior incidência de doenças específicas, como mal de Chagas, leishmaniose e altas taxas de infecção por tuberculose, que acomete 1 em cada 5 portadores de AIDS. Além dessas, há doenças que ocasionam alterações de humor e sintomas neurológicos, uma vez que atingem o Sistema Nervoso Central, como neurotoxoplasmose e meningite tuberculosa, que também provocam danos psiquiátricos e cognitivos para portadores do HIV (17).

Ademais, existem manifestações neurológicas importantes causadas não somente por agentes etiológicos externos, mas diretamente relacionadas ao retrovírus, como a demência inicial ao HIV (18), que se manifesta quando o SNC é infectado e causa sintomas mais proeminentes, como letargia, apatia e isolamento social $(19,20)$. Esse quadro frequentemente é confundido com um caso isolado de depressão (especialmente porque, quando se trata de idosos, é raro que HIV seja cogitado) e é extremamente frequente em pacientes contaminados, emergindo após o diagnóstico ou durante o curso da infecção. $O$ fator da depressão é bastante relevante quando se fala de soropositivos, porque autores como Malbergier (21), Teng, Humes e Demétrio (22), e Ventura (23) 
concordam que pacientes portadores de doenças crônicas, quando comparados à maioria da população, apresentam prevalência maior de transtornos psiquiátricos, principalmente a depressão (24). A importância dessa discussão se dá pelo fato deque esses transtornos, e a depressão especialmente, podem diminuir drasticamente a chances de graus satisfatórios de adesão a um tratamento complexo e duradouro, como é o tratamento antirretroviral.

Essa complexidade demanda que o portador de HIV receba cuidados específicos e dependa do acompanhamento com um grupo multidisciplinar de profissionais da saúde, pois o TARV exige mudanças significativas de hábitos, sendo necessário estabelecer uma nova rotina. Dessa forma, deve haver um compartilhamento das escolhas entre o portador, a equipe e a rede de relações sociais do indivíduo e é necessário o reconhecimento das atribuições de cada um, além de ser extremamente importante que a equipe procure compreender qual é o entendimento do paciente sobre a própria enfermidade (25).

\section{Visão dos idosos com HIV/AIDS}

Quando ganhou visibilidade em meados da década de 80 (26), a AIDS era estritamente vinculada a homossexuais, profissionais do sexo, travestis e viciados em drogas, porém, raramente aos idosos. Apesar dos preconceitos sociais, o vírus afeta todas as faixas etárias, e o referido grupo está se tornando cada vez mais exposto a essa infecção. Fatores como o não uso de preservativos, falha na comunicação dos profissionais de saúde e falta de conhecimento acerca da doença são essenciais para explicar essa atual vulnerabilidade.

O uso do preservativo não era uma prática comum quando esses idosos iniciaram sua vida sexual (27), portanto, esse comportamento os coloca em uma situação de vulnerabilidade em relação ao vírus da AIDS. Os fatores que levam a mulher idosa a não utilizar o preservativo são: a crença na fidelidade do parceiro e segurança por estar em uma relação monogâmica estável, a interferência na qualidade da relação e a associação desse exclusivamente para a prevenção da gravidez, sendo desnecessário após a menopausa (27). Já os idosos do sexo masculino, em sua maioria, relacionam a AIDS exclusivamente a homossexuais, travestis e profissionais do sexo (27).

A falha na comunicação entre o profissional da saúde e o idoso, no que concerne seus hábitos sexuais, está relacionada ao entendimento desse como um ser assexuado, desprovido de prazeres e necessidades (27). Esse prejulgamento por parte dos profissionais pode levar a um diagnóstico tardio da AIDS, pois muitos dos sintomas são associados às doenças senis. Bom exemplo para ilustrar essa lacuna na comunicação médico-paciente é um caso apresentado em um dos artigos revisados, que envolve a quebra de sigilo por parte do profissional. Após receber o resultado positivo do exame de sorologia para HIV de seu paciente, o médico informou diretamente a família, desconsiderando a participação do enfermo em seu próprio diagnóstico (28).

Há um evidente desconhecimento por parte dos idosos em relação à AIDS, especialmente no quesito da contaminação, que revela uma imprecisão na transmissão de informações confiáveis acerca da doença por órgãos de autoridade, como por exemplo o Ministério da Saúde. Apesar da maioria das infecções ter ocorrido durante a relação sexual, muitos afirmaram terem adquirindo a doença por meio de cirurgias e até mesmo através de vacinas (27).

Após o diagnóstico da AIDS, esses idosos se sentem envergonhados e culpados, sendo essencial o apoio de familiares e amigos durante o tratamento. Muitos preferem manter sigilo com receio do preconceito e discriminação por parte da sociedade, como foi relatado por um dos participantes, que foi demitido após expor sua condição para o patrão $(26,27)$. 


\section{Tratamento dos idosos}

O Tratamento Antirretroviral (TARV), que permite a supressão crônica da replicação do vírus, passou a ser amplamente usado e gratuitamente distribuído no Brasil a partir de 1996, configurando um marco no acesso universal ao tratamento da AIDS (24). Dando a essa infecção o status de doença crônica, o TARV diminuiu a incidência de infecções oportunistas, reduziu em 50\% o desenvolvimento de demência e promoveu diminuição da morbidade e mortalidade, aumentando a expectativa de vida dos pacientes (29). Em março de 2010, 200 mil pacientes estavam em uso de TARV no Brasil, (7,6) e muitos estão na segunda década de tratamento com níveis plasmáticos indetectáveis de carga viral do HIV (30). Dessa forma, o advento dessa terapêutica rompe com o estigma de que o diagnóstico da AIDS é uma sentença de morte.

A adesão ao TARV pelos portadores da AIDS ainda é um desafio, uma vez que exige a ingestão de muitos comprimidos, que devem ser conservados em baixas temperaturas, tomados em horários rígidos, além das responsabilidades decorrentes do uso desses medicamentos, em razão da necessidade de mudanças comportamentais, alimentares e do uso vitalício das medicações. Salvo os motivos referentes ao tratamento, outros também podem justificar a baixa adesão, como ausência de suporte social, baixa escolaridade, não aceitação da doença, transtornos mentais como depressão e ansiedade, uso de álcool e outras drogas e má relação com a equipe de profissionais (31). Apesar da situação descrita, resultados de um estudo recente mostram-se positivos, com adesão de até 82,3\% de um total de 142 idosos dentro da faixa etária de 60 a 69 anos, com tempo de tratamento de 15 anos (32).

À medida que a doença progride, o sistema imunológico do paciente fica enfraquecido e os sintomas clínicos começam a se manifestar, dentre eles a encefalopatia do HIV, caracterizada pelo transtorno das funções cognitivas, e que tem como consequência déficits dos processos mentais. A baixa imunidade também os deixa suscetíveis a infecções por doenças oportunistas, que podem afetar seu humor e acarretar a depressão, doença recorrente entre os pacientes soropositivos (24). Essa condição merece atenção especial, pois portadores de HIV/AIDS com depressão de moderada a grave apresentam risco $95 \%$ maior de ter problemas com a adesão ao tratamento antirretroviral, levando à progressão da doença, impactando negativamente na qualidade de vida e aumentando a mortalidade $(33,34)$.

As comorbidades advindas do tratamento, do envelhecimento e da própria infecção tem um grande impacto na vida daquele que vive com a doença, visto que os abalos causados ao organismo são severos a ponto de causar algo como um "envelhecimento precoce". Ainda mais se combinados a um estilo de vida que inclua o uso de álcool, drogas e tabagismo, que sozinhos já exigiriam muito do corpo. Alguns exemplos dessas comorbidades são: doenças cardiovasculares, insuficiência renal e cognitiva, diminuição da densidade mineral óssea, hipertensão, depressão, doenças articulares, diabetes, entre outros (32).

Com isso, é preciso que o idoso se sinta amparado em relação a sua condição sorológica, recebendo o apoio de familiares e profissionais da saúde, além de buscar suporte emocional em suas crenças e em sua espiritualidade para minimizar o sofrimento causado pelo diagnóstico e os desafios do tratamento (16). Esse amparo, que deve ser ofertado por toda a equipe multidisciplinar da saúde que acompanhe o caso desde o momento do diagnóstico, faz com que a adesão ao tratamento melhore, além de diminuir o estigma em relação a esse grupo. O idoso deve ser estimulado a realizar atividades de lazer ou que incrementem em sua qualidade de vida, podendo, sempre que possível, contar com 


\section{Vittalle - Revista de Ciências da Saúde v. 33, n. 2 (2021) 109-121}

engajamento familiar e de pessoas próximas (13).

\section{Conclusão}

A partir das análises dos artigos selecionados para a revisão integrativa, observamos que mesmo depois de três décadas desde a descrição do HIV no Brasil, um dos principais fatores que interferem na qualidade de vida dos portadores do vírus ainda é relacionado ao preconceito com o diagnóstico. No caso dos idosos, o preconceito é particularmente nocivo, uma vez que provém não só da sociedade como também dos próprios profissionais de saúde, afetando diretamente o diagnóstico e tratamento. Além disso, o estigma por parte dos pacientes muitas vezes os leva ao isolamento social e familiar, tornando a realidade bastante solitária.

O preconceito é reflexo da falta de informação, e a análise dos artigos apontou falhas significativas por parte do sistema de saúde brasileiro tanto na formação dos profissionais quanto na divulgação de informações sobre o HIV relacionados à prevenção. Assim, é desejável que haja um maior cuidado na estratégia de abordagem do HIV/AIDS no sistema de saúde para que além de evitar que o número de novos casos de idosos contaminados siga crescendo, a qualidade de vida dos portadores da doença apresente uma melhoria.

\section{Referências}

1. de Araujo VLB, Brito DMS, Gimeniz MT, Queiroz TA, Tavares CM. Características da Aids na terceira idade em um hospital de referência do Estado do Ceará, Brasil. Rev Bras Epidemiol. 2007; 10(4): 544-54.

2. Ministério da Saúde (Brasil). Departamento Doenças de Condições Crônicas e Infecções Sexualmente Transmissíveis. Boletim Epidemiológico HIV/Aids 2020. Brasília (DF): Ministério da Saúde; 2020.

3. Instituto Brasileiro de Geografia e Estatística. Síntese de Indicadores Sociais: uma análise das condições de vida da população brasileira. Informação demográfica e socioeconômica. Ministério do Planejamento, Orçamento e Gestão; 2010.

4. Centers for disease control and prevention. Older People and HIV: How many older people have Aids? International Association of Providers of Aids Care. 2014.

5. Ministério da Saúde (Brasil). Cuidado integral às pessoas que vivem com HIV pela Atenção Básica: manual para a equipe multiprofissional. Brasília (DF): Ministério da Saúde; 2017.

6. Casseb J, editor. HIV/AIDS. São Paulo: Atheneu, 2010.

7. Hallal R, Ravasi G, Kuchenbecker R, Greco D, Simão M. O acesso universal ao tratamento antirretroviral no Brasil. Rev Tempus Actas Saúde Coletiva. 2010; 4(2):53-65.

8. Lima TC, Freitas MIP. Comportamentos em saúde de uma população portadora do HIV/AIDS. Rev Bras Enferm. 2012; 65(1):110-5.

9. Cardoso SW, Torres TS, Santini-Oliveira M, Marins LMS, Veloso VG, Grinsztejn B. Aging with HIV: a practical review. Braz J Infect Dis. 2013; 17(4):464-479.

10. Sepkowitz KA. AIDS - The First 20 Year. N Engl J Med. 2001; 344: 1764-1772.

11. Tavares MC de A, Leal MCC, Marques AP de O, Zimmermann R. D. Social support for the elderly with HIV/Aids: an integrative review. Rio de Janeiro, Rev. bras. geriatr. Gerontol. 2019; 22(2): e180168.

12. Cassette JB, da Silva LC, Felício EEAA, Soares LA, de Morais RA, Prado TS, et al. HIV/AIDS em idosos: estigmas, trabalho e formação em saúde. Rev Bras Geriatr Gerontol. 2016; 19(5):733-44.

13. Santana PPC, Andrade M, Almeida VS, Menezes HF, Teixeira PA. Fatores Que Interferem Na Qualidade De Vida De Idosos Com Hiv/Aids: Uma Revisão Integrativa. Cogitare Enfermagem. 2018; 23 (4).

14. Alencar RA, Ciosak SI. AIDS in the elderly: reasons that lead to late diagnosis. Ver Bras Enferm. 2016; 69(6): 1076-81.

15. Ferro AP, Guilhermino GM, Lima AC, Maciel MP. Perfil da síndrome da imunodeficiência adquirida em idosos. Rev. iberoam. educ. investi. Enferm. 2016; 6(1): 49-55.

16. Barros TS, Miranda KCL, Coelho M de MF. Idosos com HIV/AIDS: compreendendo a base ideológica de suas vivências. UERJ. Rev. Enferm. 2018; 26: e12978-e12978. 
17. Christo PP. Alterações cognitivas da infecção pelo HIV e AIDS. Rev Assoc Med Bras. 2010; 56(2): 242-7.

18. Ranga U, Shankarappa R, Siddappa NB, Ramakrishna L, Nagendran R, Mahalingam M, et al. Tat protein of human immunodeficiency virus type 1 subtype $\mathrm{C}$ strains is a defective chemokine. J Virol. 2004; 78(5): 2586-90.

19. Ranga U, Shankarappa R, Siddappa NB, Ramakrishna L, Nagendran R, Mahalingam M, et al. Tat protein of human immunodeficiency virus type 1 subtype $\mathrm{C}$ strains is a defective chemokine. $\mathrm{J}$ Virol. 2004; 78(5): 2586-90.

20. Botega NJ, organizador. Prática psiquiátrica no hospital geral: interconsulta e emergência. 2a ed. Porto Alegre: Artmed; 2006.

21. Malbergier A. Aids e psiquiatria: um guia para os profissionais de saúde. Rio de Janeiro: Revinter 2000.

22. Teng CT, Humes EC, Demétrio FN. Depressão e comorbidades clínicas. Ver Psiq Clin. 2005; 32(3): 149-59.

23. Ventura T. Depressão e comorbidade: um caso clínico. Rev Port Clin Geral. 2011; 27(1): 36-42.

24. Leite MA. Depressão, qualidade de vida e adesão ao tratamento antirretroviral em idosos portadores de HIV/Aids [Dissertação]. São Paulo: Secretaria de Estado da Saúde de São Paulo; 2016.

25. Russell CK, Bunting SM, Graney M, Hartig MT, Kisner P, Brown B. Factors that influence the medication decision making of persons with HIV/AIDS: a taxonomic exploration. J Assoc Nurses AIDS Care 2003;14(4): 46- 60.

26. Araldi LM, Pelzer MT, Gautério-Abreu DP, Saioron I, Santos SSC, S Ilha. Pessoas idosas com o vírus da imunodeficiência humana: infecção, diagnóstico e convivência. REME - Rev Min Enferm. 2016; 20:e948.

27. dos Anjos KF, Oliveira AC, Suto CSS, et al. Bioethical issues involved in care of elderly with HIV/AIDS. Rev Fund Care Online. 2016; 8(3):4882-4890.

28. Alencar RA, Ciosak SI. Late diagnosis and vulnerabilities of the elderly living with HIV/AIDS. Revista da Escola de Enfermagem. 2015; 49(2): 229-235.

29. Sacktor N. The epidemiology of human immunodeficiency virus-associated neurological disease in the era of highly active antiretroviral therapy. J Neurovirol. 2002;8 (Suppl 2):115-21.

30. Richman DD, Margolis DM, Delaney M, Greene WC, Hazuda D, Pomerantz RJ. The challenge of finding a cure for HIV infection. Science. 2009; 323(5919):1304-7.

31. Adão VM, Caraciolo JMM. Fatores que influenciam a adesão aos antiretrovirais. In: Caraciolo JMM, Shimma E, coordenadores. Adesão da teoria à prática: experiências bem sucedidas no Estado de São Paulo. São Paulo: CRT DST/AIDS-SP. 2007; 28-41.

32. Cruz GECP, Ramos LR. Limitações funcionais e incapacidades de idosos com síndrome de imunodeficiência adquirida. Acta Paulista de Enfermagem. 2015; 28(5): 488-493

33. Starace F, Ammassari A, Trotta MP, Murri R, De Longis P, Izzo C, et al. Depression is a risk factor for suboptimal adherence to highly active antiretroviral therapy. J Acquir Immune Defic Syndr 2002; 31(Suppl 3): S136-9.

34. Malbergier A. AIDS e saúde mental. J Bras Aids 2006; 7(6): 281-7. 
Vittalle - Revista de Ciências da Saúde v. 33, n. 2 (2021) 109-121

EDITORA E GRÁFICA DA FURG

CAMPUS CARREIROS

CEP 96203900

editora@furg.br 